\title{
Kinetics of the Regeneration by lodide of Dye Sensitizers Adsorbed on Mesoporous Titania
}

\author{
Joël Teuscher, ${ }^{*,+, \dagger}$ Arianna Marchioro, ${ }^{\dagger, \ddagger}$ Julien Andrès, ${ }^{\dagger}$ Loïc M. Roch, ${ }^{\dagger}$ Mingfei Xu, ${ }^{\S}$
} Shaik M. Zakeeruddin, ${ }^{\ddagger}$ Peng Wang, ${ }^{\S}$ Michael Grätzel, ${ }^{\ddagger}$ and Jacques-E. Moser

\begin{abstract}
${ }^{\dagger}$ Photochemical Dynamics Group, Institute of Chemical Sciences and Engineering, École polytechnique fédérale de Lausanne, CH-1015 Lausanne, Switzerland

${ }^{\ddagger}$ Laboratory for Photonics and Interfaces, Institute of Chemical Sciences and Engineering, École polytechnique fédérale de Lausanne, CH-1015 Lausanne, Switzerland

${ }^{\S}$ State Key Laboratory of Polymer Physics and Chemistry, Changchun Institute of Applied Chemistry, Chinese Academy of Science, Changchun, Jilin 130022, China
\end{abstract}

\section{Supporting Information}

ABSTRACT: Regeneration of dye sensitizer molecules by reducing species contained in the electrolyte is a key mechanism in liquid dye-sensitized solar cells because it competes kinetically with a detrimental charge recombination process. Kinetics of the reduction by iodide ions of the oxidized states $\left(\mathrm{S}^{+}\right)$of two $\mathrm{Ru}^{\mathrm{II}}$ complex dyes and four organic $\pi$ conjugated bridged donor-acceptor sensitizers were examined as a function of the electrolyte concentration. Results show that two different cases can be distinguished. A sublinear behavior of the regeneration rate and a plateau value reached at high bulk iodide concentrations were found for N820 ruthenium dye and interpreted as being due to an associative interaction involving the formation of $\left(\mathrm{S}^{+}, \mathrm{I}^{-}\right) \cdots \mathrm{I}^{-}$surface complexes prior to the reaction. On the other hand, feeble reaction rates at low electrolyte concentrations and a superlinear behavior are observed predominantly for the organic dyes, pointing to a repulsive interaction between the dyed surface and iodide anions. At higher iodide bulk concentration, a linear behavior is reached, providing an estimate of a second-order rate

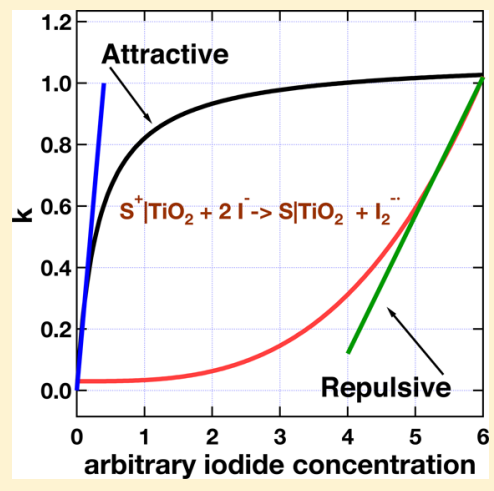
constant. A correlation of these two opposite behaviors with the structure of the dye is observed, emphasizing the role of sulfur atoms in the association of $\mathrm{I}^{-}$anions in the dye-sensitized layer. These findings allow for a better understanding of the dye-electrolyte interaction and of the effect of the iodide concentration on the photovoltaic performances of dye-sensitized solar cells.

\section{INTRODUCTION}

Dye-sensitized solar cells (DSSCs) can efficiently convert solar light into electricity. ${ }^{1}$ In this type of photovoltaic device, absorption of light by a molecular dye adsorbed at the surface of a mesoporous oxide film anode, such as $\mathrm{TiO}_{2}$, is followed by electron injection from the dye's electronic excited state into the conduction band of the solid. ${ }^{2}$ This primary charge separation step takes place on an ultrafast time scale with a time constant of a few femtoseconds for the most efficient dye sensitizers. ${ }^{3,4}$ Charge recombination between the injected electron and the positive charge left on the oxidized dye is a much slower process, as it typically occurs in the microsecondmillisecond time scale. ${ }^{5}$ This energy-wasting reaction is prevented by quickly regenerating the oxidized dye by a redox mediator, whose function is to reduce the dye sensitizer back to its original state and to transport positive charges to a counter electrode. State-of-the-art devices using triiodide/ iodide redox couple in combination with ruthenium polypyridyl complexes or organic dye sensitizers exhibit photovoltaic power conversion efficiencies over $11 \%{ }^{6,7}$
Triiodide/iodide redox couple $\left(\mathrm{I}_{3}^{-} / \mathrm{I}^{-}\right)$is endowed with several interesting properties. It has a suitable redox potential allowing for efficient dye regeneration, and it does not absorb much light. Electrolytes with very high iodide concentrations up to $6 \mathrm{~mol} \mathrm{~L}^{-1}$ can be obtained using a pure iodide ionic liquid or by dissolving it in an appropriate solvent. The reduction of the triiodide species by photoinjected electrons on the surface of $\mathrm{TiO}_{2}$ is very slow and therefore limits the cathodic dark current because of this energy-wasting recombination process. ${ }^{8}$ Other electrolytes, based on one-electron redox couples, such as in particular $\left[\mathrm{Co}(\mathrm{bpy}-\mathrm{pz})_{2}\right]^{3+/ 2+}$, have been shown recently to allow for improved conversion efficiencies. ${ }^{9,10}$ However, in contrast with these mediators, the two-electron $\mathrm{I}_{3}{ }^{-} / \mathrm{I}^{-}$couple is not reversible on the F-doped tin oxide film typically coating the transparent conductive glass electrode, on top of which the $\mathrm{TiO}_{2}$ mesoporous layer is deposited. As the electrolyte

Special Issue: Michael Grätzel Festschrift

Received: February 11, 2014

Revised: April 16, 2014

Published: April 21, 2014 
penetrating into the pores of the oxide anode can always come into contact with the conductive glass, this unique advantage prevents short-circuits and alleviates the need for depositing a dense oxide blocking underlayer between the F-doped $\mathrm{SnO}_{2}$ coated glass and the mesoporous $\mathrm{TiO}_{2}$ film. ${ }^{5}$

Reaction Scheme. Following ultrafast electron photoinjection into the oxide semiconductor (eq 1), the reduction of the oxidized sensitizer $\mathrm{S}^{+}$by a mediator $\mathrm{M}$ (eq 2 ) is particularly important as it competes kinetically with the detrimental back electron-transfer reaction (eq 3 ).

$$
\begin{aligned}
& \mathrm{SlTiO}_{2}+h \nu \rightarrow \mathrm{S}^{*} \mid \mathrm{TiO}_{2} \rightarrow \mathrm{S}^{+} \mathrm{TiO}_{2}+\mathrm{e}_{\mathrm{cb}}^{-}\left(\mathrm{TiO}_{2}\right) \\
& \mathrm{S}^{+} \mathrm{TiO}_{2}+\mathrm{M} \rightarrow \mathrm{SlTiO}_{2}+\mathrm{M}^{+} \\
& \mathrm{S}^{+} \mathrm{TiO}_{2}+\mathrm{e}_{\mathrm{cb}}^{-}\left(\mathrm{TiO}_{2}\right) \rightarrow \mathrm{SlTiO}_{2}
\end{aligned}
$$

The chemical particulars of iodide oxidation with transitionmetal compounds in solution have been known for a long time. However, the detailed knowledge of the redox chemistry at sensitized electrodes is more recent and still incomplete. ${ }^{5}$ The present study focuses on the dynamics of the regeneration reaction at open-circuit conditions (eq 2) with $\mathrm{M} \equiv \mathrm{I}^{-}$and its dependence upon iodide concentration.

The standard oxidation potential of the fully protonated form of cis- $\left[\mathrm{Ru}^{\mathrm{II}}\left(\mathrm{dcbpyH}_{2}\right)_{2}(\mathrm{NCS})_{2}\right]$ complex dye (N3) in solution in acetonitrile, for instance, is $\varphi^{0}\left(\mathrm{~S}^{+} / \mathrm{S}\right)=+1.07 \mathrm{~V} / \mathrm{SHE}$ (standard hydrogen electrode). This value is very close to that of the standard potential $\varphi^{0}\left(\mathrm{I}^{\bullet} / \mathrm{I}^{-}\right)=+1.15 \mathrm{~V} / \mathrm{SHE}{ }^{8}$ Hence, oxidation of iodide by the oxidized dye $\mathrm{S}^{+}$yielding elementary iodine $\mathrm{I}^{\bullet}$ does not benefit from a large driving force and is likely to be a rather slow process. However, recent studies indicate that single iodide reaction mechanism yielding iodine atom formation might play a significant role in the sensitizer regeneration. ${ }^{11,12}$ Oxidation of iodide to $\mathrm{I}_{2}^{-\bullet}$ is characterized by a lower standard potential $\varphi^{0}\left(\mathrm{I}_{2}^{-\bullet} / 2 \mathrm{I}^{-}\right)=+0.8-1.0 \mathrm{~V} /$ SHE. ${ }^{13}$ Because of a driving force of $70-270 \mathrm{meV}$, eq 4 is thermodynamically more favorable and is thus expected to be the preferred pathway for the dye regeneration reaction.

$$
\begin{aligned}
& \mathrm{S}^{+} \mathrm{TiO}_{2}+2 \mathrm{I}^{-} \rightarrow \mathrm{SlTiO}_{2}+\mathrm{I}_{2}^{-\bullet} \\
& \mathrm{S}^{+} \mathrm{TiO}_{2}+\mathrm{I}^{-} \cdots \mathrm{I}^{-} \rightarrow \mathrm{SlTiO}_{2}+\mathrm{I}_{2}^{-\bullet} \\
& \mathrm{S}^{+}\left|\mathrm{TiO}_{2}+\mathrm{I}^{-} \rightleftarrows\left(\mathrm{S}^{+}, \mathrm{I}^{-}\right)\right| \mathrm{TiO}_{2} \\
& \left(\mathrm{~S}^{+}, \mathrm{I}^{-}\right) \mathrm{ITiO}_{2}+\mathrm{I}^{-} \rightarrow \mathrm{SlTiO}_{2}+\mathrm{I}_{2}^{-\bullet} \\
& 2 \mathrm{I}_{2}^{-\bullet} \rightarrow \mathrm{I}^{-}+\mathrm{I}_{3}^{-}
\end{aligned}
$$

Although involving the exchange of one electron, this process entails the simultaneous reaction of two $\mathrm{I}^{-}$anions with one $\mathrm{S}^{+}$. One could conceive that in highly concentrated electrolyte solutions and ionic liquids, $\mathrm{I}^{-}$ions come so close to each other that concerted electron-transfer and bond formation reactions to yield $\mathrm{I}_{2}^{-}$become possible (eq 5). In the general case, however, the most likely mechanism would rather require a rapid association pre-equilibrium established between the oxidized dye and iodide to form $\left(\mathrm{S}^{+}, \mathrm{I}^{-}\right)$pairs (eq 6). Further reaction of $\left(\mathrm{S}^{+}, \mathrm{I}^{-}\right)$pair with $\mathrm{I}^{-}$can then proceed by a bimolecular mechanism to yield $\mathrm{I}_{2}^{-\bullet}$ species (eq 7), which eventually disproportionates to produce $\mathrm{I}^{-}$and $\mathrm{I}_{3}^{-}$(eq 8). This bimolecular process is shown to be, kinetically and thermodynamically, the limiting step in the overall regeneration reaction. ${ }^{14}$ The literature is very rich in tentative explanations about the interception mechanism of oxidized ruthenium dye. ${ }^{5,15,16}$ However, reports of interception dynamics for organic $\pi$-conjugated bridged donor-acceptor (D- $\pi$-A) dye remain poor. ${ }^{17}$ In particular, the formation of the initial $\left(\mathrm{S}^{+}, \mathrm{I}^{-}\right)$ pair mechanism remains ill defined.

lodide-Dye Interactions. Dyes, either in their ground or excited states, might bind iodide species, especially in the case of ruthenium dyes. ${ }^{18}$ The reaction of a ruthenium dye either in its ground state or oxidized form with one iodide ion might lead to the formation of an intermediate complex. ${ }^{19,20}$ Computational studies demonstrated that an iodide anion in the vicinity of an isothiocyanate ligand can have its electron already partially delocalized into the dye. ${ }^{21}$

The interception of oxidized ruthenium tris(bipyridyl) dye also suggested a difference between the bulk iodide concentration and the concentration in the vicinity of the dye, revealing the importance of the titania surface charge. ${ }^{22}$ This has been highlighted as the dye regeneration appears to be faster when using cations such as $\mathrm{Li}^{+}$in the electrolyte, favoring higher local concentration of iodide in the $\mathrm{TiO}_{2}$ vicinity because of the adsorption of lithium cations onto the surface. ${ }^{19}$ In the case of a ruthenium phtalocyanine, the formation of a complex with iodine is postulated, leading to a local increase of iodide species. ${ }^{23}$ Isothiocyanate groups contained in state-ofthe-art ruthenium dyes can be released from the dye and form a complex with iodine species as observed by Raman spectroscopy. ${ }^{24}$ Interactions of iodide species with the reduced and oxidized states of the dye cis-bis(isothiocyanato) bis $\left(2,2^{\prime}\right.$ bipyridyl-4,4'-dicarboxylato ruthenium(II) (N3) have been investigated by means of density functional theory (DFT) ${ }^{25,26}$ Also, adduct formation with iodine has been studied by X-ray diffraction. ${ }^{27}$ These studies reveal interactions between iodide or iodine and the sulfur atom of the isothiocyanate ligand as well as ligand-exchange reactions between $\mathrm{I}^{-}$and $\mathrm{SCN}^{-}$moieties. Interaction of iodide with bipyridyl rings of the dye is also proposed.

In the case of $\pi$-conjugated bridged donor-acceptor (D- $\pi$-A) organic dyes, the absence of isothiocyanate groups leads to the consideration of other interaction sites. Organic dyes that exhibit good cell performance have a $\pi$-conjugated bridge that contains thiophene units or its derivatives. ${ }^{28}$ Sulfur atoms, once more, might therefore constitute potential binding sites for iodide anions.

Concentration Dependence of Regeneration Kinetics. The first report of $\mathrm{Ru}^{\mathrm{II}}$-polypyridyl compound regenerated by iodide on the surface of titania, using potassium iodide aqueous solution, was published in $1988 .^{29}$ Since this first study, there have been many efforts to abstract the rate at which the dye ground state is regenerated. Knowledge about the regeneration mechanism is crucial to DSSC development; the relationship between the dye structure and the regeneration rate is especially relevant to dye design. Reports use transient absorption spectroscopy based on the oxidized dye absorption or ground-state bleaching because they are good probes for quantifying rate constants; however, more detailed studies are needed to provide reliable information regarding the intrinsic mechanisms underlying the reduction. Anderson et al. have proposed a detailed protocol for determining the kinetics of the oxidation of iodide and found a first-order reaction for iodide regeneration. ${ }^{16}$ This study involves measurement at shortcircuit on complete DSSC devices and at iodide concentrations lower than that in the present study, rendering extensive comparison difficult. 
In general, and based on the $\mathrm{N} 3-\mathrm{TiO}_{2}$ system, the use of a low concentration of iodide leads to regeneration kinetics being first-order with respect to iodide concentration, whereas at higher concentrations, a static component is often observed. For oxidized $\mathrm{Ru}$ bipyridyl complex dye in the presence of 0.5 mol L ${ }^{-1} \mathrm{I}^{-}$, the typical regeneration reaction time constant lies in the range of $1 \mu \mathrm{s} .{ }^{19}$ Regeneration of $\mathrm{Z} 907 \mathrm{Na}$, a dinonyl amphiphilic derivative of $\mathrm{N} 3$, on the surface of dye-sensitized mesoporous titania electrodes has been probed with transient absorbance spectroscopy as a function of the iodide concentration. A repulsive interaction between the sensitized $\mathrm{TiO}_{2}$ surface and iodide was inferred, which emphasizes the need for a sufficient iodide concentration to quantitatively regenerate the dye. ${ }^{30}$ At moderate iodide concentrations $\left(\left[\mathrm{I}^{-}\right]\right.$ $\left.\leq 0.1 \mathrm{~mol} \mathrm{~L}^{-1}\right)$, the kinetic redundancy between the regeneration (eq 7) and the recombination (eq 3) is still important; therefore, results obtained at iodide concentration greater than $0.1 \mathrm{~mol} \mathrm{~L}^{-1}$ represent the regeneration reaction decoupled from the back electron transfer. ${ }^{31}$

In the present work, we studied the regeneration of oxidized dyes by iodide for two amphiphilic ruthenium dyes, N820 and Z907Na, varying the length of substituent alkyl chains and therefore the accessibility of the reaction site. A base was conjointly used to modify the adsorption of the dye and therefore the dye concentration on the surface. We also report on regeneration dynamics of a series of four organic D- $\pi$-A dyes (C201, C203, C204, and C205) having various bridge units affecting the iodide approach and association possibilities. The rate of regeneration of the dye by the electrolyte was probed by time-resolved absorption spectroscopy, while the iodide bulk concentration in the electrolyte was systematically varied between $0.1 \mathrm{~mol} \mathrm{~L}^{-1}$ and $6.1 \mathrm{~mol} \mathrm{~L}^{-1}$. Significantly different behaviors were observed for the various dyes, suggesting two types of mechanisms for the reduction of oxidized dye species by iodide at the surface of mesoporous titania.

\section{EXPERIMENTAL METHODS}

Dyes. Two amphiphilic ruthenium dyes were used in this study, Z907Na (sodium[cis-bis(thiocyanato)-(2,2'-bipyridyl-4carboxylate- $4^{\prime}$-carboxylic acid) (4,4'-dinonyl-2,2'-bipyridyl)ruthenium(II)]) and N820 (cis-bis(thiocyanato)-(2,2'-bipyridyl-4,4'-dicarboxylic acid) (4,4'-dimethyl-2,2' -bipyridyl)ruthenium(II)). These dyes have alkyl substituents of different lengths (nonyl and methyl groups, respectively) grafted onto the bipyridyl ligand that faces the surrounding medium. They exhibit similar absorption spectra, as the chromophore groups are identical.

A series of four organic dye sensitizers, coded C201, C203, C204, and C205, was also studied. ${ }^{28,32,33}$ These are D- $\pi$-A organic dyes with the same donor and anchoring groups. Their common core is $3-\left\{5^{\prime}-[N, N\right.$-bis $(9,9-$ dimethylfluorene-2-yl)phenyl]-(bridge)-5-yl\}-2-cyanoacrylic acid. The triarylamine moiety is a hole-acceptor unit often found in organic optoelectronics. ${ }^{34}$ The $\pi$-conjugated bridge unit is composed of two or three fused thiophene rings for C201 and C203, respectively. In C204 and C205, one and two 3,4-ethylenedioxythiophene (EDOT) moieties are present, respectively.

Electrolytes. The electrolyte used in this study was based on iodide-reducing species. It was made by diluting 1,3propylmethylimidazolium iodide (PMII) pure ionic liquid in 3methoxypropionitrile (MPN) solvent. This allowed the preparation of solutions with iodide concentration ranging from 0 to $6.1 \mathrm{~mol} \mathrm{~L}^{-1}$
Titanium Dioxide. Anatase titanium dioxide mesoporous films of 4.8 to $9.6 \mu \mathrm{m}$ thickness were used. A paste containing $\mathrm{TiO}_{2} 16 \mathrm{~nm}$ diameter particles (14 wt \%), a polymer (ethylcellulose), and various additives was prepared. The paste was doctor-bladed onto a glass substrate and then calcined at a temperature of $470{ }^{\circ} \mathrm{C}$ for $25 \mathrm{~min}$. The resulting layer had a porosity of 0.625 , allowing for a high dye uptake.

Samples. Films were immersed overnight in a $0.5 \mathrm{mmol} \mathrm{L}^{-1}$ dye ethanolic dye solution. Prior to being dyed, the films were briefly heated to $200{ }^{\circ} \mathrm{C}$ to remove residual water trapped within the porous network and therefore favor the subsequent dye adsorption. After being dyed, the films were rinsed with ethanol and covered with the desired electrolyte and a thin glass plate.

Transient Absorbance Spectroscopy. An optical parametric oscillator (OPO-355, GWU) was pumped by a Continuum Powerlite 7030 frequency-tripled Q-switched Nd:YAG laser $(\lambda=355 \mathrm{~nm} ; 30 \mathrm{~Hz}$ repetition rate, $3 \mathrm{~W}$ average power). The output of the OPO ( $5 \mathrm{~ns}$ full width at halfmaximum) was typically tuned at wavelengths between 530 and $650 \mathrm{~nm}$ to excite the dye sensitizer adsorbed on $\mathrm{TiO}_{2}$. The beam was expanded to cover the whole sample, and its energy was attenuated down to a fluence below $30 \mu \mathrm{J} \mathrm{cm}^{-2}$, corresponding to the injection on the average of less than one electron per nanoparticle. The output of a xenon arc lamp, filtered through a monochromator and various filters, constituted the probe beam. It was focused onto the sample on a typical $0.2 \mathrm{~cm}^{2}$ area and then collected through a second monochromator. Both monochromators were tuned at the desired probe wavelength. A fast photomultiplier tube (R9110, Hamamatsu), only 3 dynodes of which were used, detected the probe light. A digital signal analyzer (DSA 602 A, Tektronix) then recorded the induced transient electrical signal. Averaging over ca. 2500 laser shots was typically required to obtain a satisfactory signal-to-noise ratio (Figure S1 of Supporting Information).

\section{RESULTS AND DISCUSSION}

Ruthenium Dyes. Nanosecond time-resolved transient absorption spectroscopy was applied to N820- and Z907Nasensitized $\mathrm{TiO}_{2}$ films covered by pure MPN solvent. Upon pulsed laser excitation at $\lambda=600 \mathrm{~nm}$, the oxidized form $S^{+}$of both dyes, resulting from the ultrafast charge injection into the titanium dioxide conduction band (eq 1), was observed by monitoring its optical absorption at probe wavelengths of 650 and $680 \mathrm{~nm}$, respectively. ${ }^{30,35}$ In the absence of the redox mediator, the $\mathrm{S}^{+}$population decays in the microsecondmillisecond time-scale because of the back electron-transfer process (eq 3). An experimental half-reaction time $t_{1 / 2}=60 \mu \mathrm{s}$ was measured for N820 dye-sensitized mesoporous $\mathrm{TiO}_{2}$ in pure $\mathrm{MPN} .{ }^{36}$ Provided the excitation fluence is kept very low, as to ensure that the average number of electrons injected per $\mathrm{TiO}_{2}$ nanoparticle is less than 1 , the observed kinetics is essentially exponential, and a first-order rate constant $k_{\mathrm{b}}=$ $\ln (2) / t_{1 / 2}=1.16 \times 10^{4} \mathrm{~s}^{-1}$ is inferred. In a redox-active electrolyte with $0.1 \mathrm{~mol} \mathrm{~L}^{-1}$ iodide, the decay of the oxidized dye population becomes significantly faster, with $k=3.0 \times 10^{4}$ $\mathrm{s}^{-1}$. This dynamics is assigned to the regeneration reaction (eq 4) and is sufficiently fast to be decoupled from the back electron-transfer process. The $\mathrm{Z} 907 \mathrm{Na}$ oxidized species has an experimental half-lifetime of $400 \mu \mathrm{s}\left(k_{\mathrm{b}}=1.7 \times 10^{3} \mathrm{~s}^{-1}\right)$ in MPN, about seven times longer than that of N820. The nonyl chains attached to one of the bipyridyl ligands of Z907Na dye 
apparently result in an increase of the distance from the $\mathrm{TiO}_{2}$ surface to the $\mathrm{Ru}^{3+}$ center over which back electron transfer has to take place. Long hydrophobic alkyl chains are responsible for the increased stability of the dye sensitizer in DSSCs. ${ }^{37}$ They tend, however, to constitute a barrier for the approach of iodide anions that have to reach the $\mathrm{Ru}^{3+}$ center of the oxidized dye to reduce it to $\mathrm{Ru}^{2+}$. This effect is evidenced by the regeneration dynamics of $\mathrm{Z} 907 \mathrm{Na}$, whose rate constant is reduced by a factor of 10 compared to that of the reaction with the reference dye $\mathrm{N} 3{ }^{30}$ With $\left[\mathrm{I}^{-}\right]=0.5 \mathrm{~mol} \mathrm{~L}^{-1}$, the observed rate constant for the regeneration of the oxidized $\mathrm{Z} 907 \mathrm{Na}$ dye is $k_{\mathrm{r}}=1.3 \times 10^{4}$ $\mathrm{s}^{-1}$. Increasing the iodide bulk concentration in the electrolyte increases the rate constant for the reaction significantly: $1 / t_{1 / 2}=$ $5.3 \times 10^{4} \mathrm{~s}^{-1}$ for $\left[\mathrm{I}^{-}\right]=1.5 \mathrm{~mol} \mathrm{~L}^{-1}$ and $1 / t_{1 / 2}=1.42 \times 10^{5} \mathrm{~s}^{-1}$ for $\left[\mathrm{I}^{-}\right]=2.5 \mathrm{~mol} \mathrm{~L} \mathrm{~L}^{-1}$ were measured.

According to eq 4, a third-order kinetics is expected for the decay of the oxidized dye species, whose one-electron reduction involves the oxidation of $\mathrm{I}^{-}$to $\mathrm{I}_{2}^{-}$. In the range of concentration reported in this study, iodide anions are present in large excess compared to $\mathrm{S}^{+}$species produced by the light-induced electron injection process. Typically at a bulk concentration $\left[\mathrm{I}^{-}\right]_{\mathrm{b}}=1.0$ mol L ${ }^{-1}$, more than 2000 iodide anions are available per oxidized dye. $\left[\mathrm{I}^{-}\right]_{\mathrm{b}}$ can therefore be considered as being constant throughout the process, yielding a pseudo-first-order rate law:

$$
-\mathrm{d}\left[\mathrm{S}^{+}\right] / \mathrm{d} t=k_{3} \cdot\left[\mathrm{S}^{+}\right] \cdot\left[\mathrm{I}^{-}\right]_{\mathrm{b}}^{2}=k_{1} \cdot\left[\mathrm{S}^{+}\right]
$$

with $k_{1}=k_{3} \cdot\left[\mathrm{I}^{-}\right]_{\mathrm{b}}^{2}$.

If the reaction involves a sufficiently fast pre-equilibrium regarding the association of one iodide anion with $\mathrm{S}^{+}$(eqs 6 and 7), the pseudo-first-order rate law can be expressed as

$$
-\mathrm{d}\left[\mathrm{S}^{+}\right] / \mathrm{d} t=k_{3} \cdot\left[\left(\mathrm{S}^{+}, \mathrm{I}^{-}\right)\right] \cdot\left[\mathrm{I}^{-}\right]_{\mathrm{b}}=k_{1} \cdot K_{1} \cdot\left[\mathrm{S}^{+}\right]
$$

with $K_{1}=\left[\left(\mathrm{S}^{+}, \mathrm{I}^{-}\right)\right] /\left(\left[\mathrm{S}^{+}\right] \cdot\left[\mathrm{I}^{-}\right]_{\mathrm{b}}\right)$ being the equilibrium constant for the formation of the $\left(\mathrm{S}^{+}, \mathrm{I}^{-}\right)$pair. Moreover, if $K_{1}$ is large, $\left[\left(\mathrm{S}^{+}, \mathrm{I}^{-}\right)\right] \approx\left[\mathrm{S}^{+}\right]$and eq 10 would reduce to

$$
-\mathrm{d}\left[\mathrm{S}^{+}\right] / \mathrm{d} t=k_{2} \cdot\left[\mathrm{S}^{+}\right] \cdot\left[\mathrm{I}^{-}\right]_{\mathrm{b}}=k^{\prime} \cdot\left[\mathrm{S}^{+}\right]
$$

with $k^{\prime}=k_{2} \cdot\left[\mathrm{I}^{-}\right]_{\mathrm{b}}$.

Figure 1 displays the values of $1 / t_{1 / 2}$ measured for N820 and $\mathrm{Z} 907 \mathrm{Na}$ as a function of the iodide bulk concentration in the

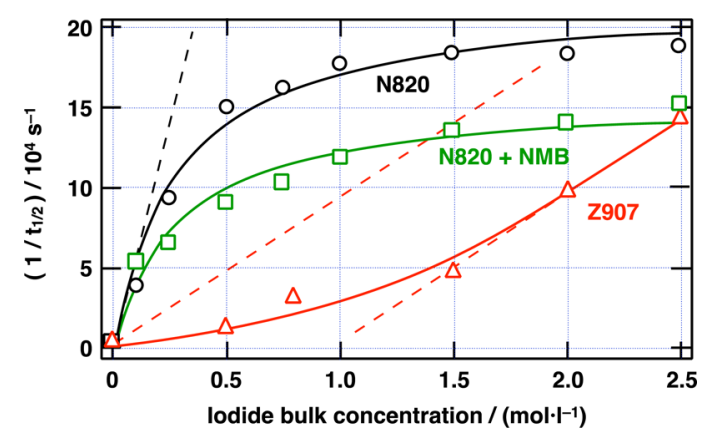

Figure 1. Inverse of the half-reaction time $1 / t_{1 / 2}$ for the regeneration of oxidized dyes measured as a function of the bulk iodide concentration. Black circles are for N820 dye, green squares for N820 with $0.5 \mathrm{~mol} \mathrm{~L}^{-1} \mathrm{NMB}$ added, and red triangles for Z907Na. Black and green solid curves are Langmuir equation fits of the data points. The black dashed line has a slope of $5.4 \times 10^{5} \mathrm{~mol}^{-1} \mathrm{~L} \mathrm{~s}^{-1}$. Data measured for $\mathrm{Z} 907 \mathrm{Na}$ dye (red triangles) are adapted from Zhang et al. ${ }^{30}$ The red dashed lines have a slope of $9.3 \times 10^{4} \mathrm{~mol}^{-1} \mathrm{~L}$ $\mathrm{s}^{-1}$. electrolyte. $\left[\mathrm{I}^{-}\right]_{\mathrm{b}}$ ranges from 0 to $2.5 \mathrm{~mol} \mathrm{~L}^{-1}$ for both dyes. PMII dilutions in MPN were used in the case of N820, with and without 1-methylbenzimidazole (NMB) $0.5 \mathrm{~mol} \mathrm{~L}^{-1}$. For $\mathrm{Z} 907 \mathrm{Na}$, the electrolyte also contained $0.15 \mathrm{~mol} \mathrm{~L}^{-1} \mathrm{I}_{2}, 0.1 \mathrm{~mol}$ $\mathrm{L}^{-1}$ guanidinium thiocyanate, and $0.5 \mathrm{~mol} \mathrm{~L}^{-1} 1$-methylbenzimidazole.

For N820, the observed rate constant increases with the iodide concentration and reaches a plateau for $\left[\mathrm{I}^{-}\right] \geq 1.5 \mathrm{~mol}$ $\mathrm{L}^{-1}$. Although the addition of NMB yields a reduced plateau value of $1 / t_{1 / 2}$, a similar concentration dependence is observed. This does not correspond to the expected linear function provided by eq 11 , where $1 / t_{1 / 2} \propto k^{\prime} \propto\left[\mathrm{I}^{-}\right]_{\mathrm{b}}$, nor to the quadratic expression of eq 10 , where $k_{1} \propto\left[\mathrm{I}^{-}\right]_{\mathrm{b}}^{2}$. The concave downward (sublinear) shape of the curve rather looks like a Langmuir isotherm function and thus suggests an associative reaction mechanism in which the second iodide anion comes in close proximity with $\left(\mathrm{S}^{+}, \mathrm{I}^{-}\right)$ion pair by adsorbing onto the dyed surface (eqs 12 and 13).

$$
\begin{aligned}
& \left(\mathrm{S}^{+}, \mathrm{I}^{-}\right)\left|\mathrm{TiO}_{2}+\mathrm{I}^{-} \stackrel{K_{\mathrm{ad}}}{\rightleftarrows}\left(\mathrm{S}^{+}, \mathrm{I}^{-}\right) \cdots \mathrm{I}_{\mathrm{s}}^{-}\right| \mathrm{TiO}_{2} \\
& \left(\mathrm{~S}^{+}, \mathrm{I}^{-}\right) \cdots \mathrm{I}_{\mathrm{s}}^{-} \mid \mathrm{TiO}_{2} \stackrel{k_{\mathrm{r}}}{\rightarrow} \mathrm{SlTiO}_{2}+\mathrm{I}_{2}^{-\bullet}
\end{aligned}
$$

Iodide surface concentration $\left[\mathrm{I}^{-}\right]_{\mathrm{s}}$ has to be considered in this case rather than the bulk concentration $\left[\mathrm{I}^{-}\right]_{\mathrm{b}}$. The rate law would then become

$$
-\mathrm{d}\left[\mathrm{S}^{+}\right] / \mathrm{d} t=k_{2} \cdot\left[\mathrm{S}^{+}\right] \cdot\left[\mathrm{I}^{-}\right]_{\mathrm{s}}=k^{\prime \prime} \cdot\left[\mathrm{S}^{+}\right]
$$

where $k^{\prime \prime}=k_{2} \cdot\left[\mathrm{I}^{-}\right]_{s} \cdot\left[\mathrm{I}^{-}\right]_{s}$ represents the apparent concentration of iodide anions present at reaction distance to $\left(\mathrm{S}^{+}, \mathrm{I}^{-}\right)$ preformed pairs on the surface. At the lowest iodide bulk concentration, adsorption of iodide onto the surface yields $\left[\mathrm{I}^{-}\right]_{\mathrm{s}}$ $>\left[\mathrm{I}^{-}\right]_{\mathrm{b}}$ and thus an observed pseudo-first-order rate constant $k^{\prime \prime}$ $>k^{\prime}$. At larger bulk iodide concentrations, saturation of the surface is attained with $\left[\mathrm{I}^{-}\right]_{\mathrm{s}}$ reaching a maximum value and implying $k^{\prime \prime}$ also reaches a plateau with $k^{\prime \prime}=k_{\max }=k_{2} \cdot\left[\mathrm{I}^{-}\right]_{\mathrm{s}, \max }$. Fitting the experimental data obtained for N820 by the Langmuir equation (eq 15) yields an adsorption equilibrium constant $K_{\mathrm{ad}}=3.4 \mathrm{M}^{-1}$ and $k_{\max }=\ln (2) \cdot\left(1 / t_{1 / 2}\right)_{\max }=2.2 \times 10^{5}$ $\mathrm{s}^{-1}$.

$$
\left[\mathrm{I}^{-}\right]_{\mathrm{s}}=\left[\mathrm{I}^{-}\right]_{\mathrm{s}, \max } \cdot \frac{K_{\mathrm{ad}} \cdot\left[\mathrm{I}^{-}\right]_{\mathrm{b}}}{1+K_{\mathrm{ad}} \cdot\left[\mathrm{I}^{-}\right]_{\mathrm{b}}} \Rightarrow k^{\prime \prime}=k_{\max } \cdot \frac{K_{\mathrm{ad}} \cdot\left[\mathrm{I}^{-}\right]_{\mathrm{b}}}{1+K_{\mathrm{ad}} \cdot\left[\mathrm{I}^{-}\right]_{\mathrm{b}}}
$$

From the value of $K_{\mathrm{ad}}$ and by postulating an activity coefficient $\gamma=1$ for $\mathrm{I}^{-}$, the adsorption binding free energy at $25{ }^{\circ} \mathrm{C}$ is estimated at $\Delta G^{0}=-R T \cdot \ln \left(K_{\mathrm{ad}} \cdot c^{0}\right)=-3.0 \mathrm{~kJ} \mathrm{~mol}^{-1}$. This value typically corresponds to that of a van der Waals attractive interaction. This indicates that a weak association exists between the second iodide anion $\left(\mathrm{I}_{\mathrm{s}}^{-}\right)$and an available site close to a $\left(\mathrm{S}^{+}, \mathrm{I}^{-}\right)$preformed pair on the surface. Upon addition of $0.5 \mathrm{~mol} \mathrm{~L}^{-1} \mathrm{NMB}$, a Lewis base, the fit of the data points by eq 15 yields parameters $K_{\mathrm{ad}}=2.8 \mathrm{M}^{-1}$ and $k_{\max }=1.7$ $\times 10^{5} \mathrm{~s}^{-1}$. This lower value of $k_{\max }$ reflects a concentration $\left[\mathrm{I}^{-}\right]_{s, \max }$ smaller than that in the absence of NMB and therefore suggests that the number of active sites likely to be occupied by iodide anions is reduced because part of the dyed surface is occupied or passivated by adsorption of NMB molecules.

The formation of $\left(\mathrm{S}, \mathrm{I}^{-}\right)$pairs prior to photoinduced charge injection and that of $\left(\mathrm{S}^{+}, \mathrm{I}^{-}\right)$involving the oxidized dye species have already been discussed. ${ }^{5,15,16}$ The isothiocyanate pseudohalide groups present on heteroleptic $\mathrm{Ru}^{\mathrm{II}}$ complex dyes in particular are believed to play an important role in offering 
binding sites to iodide anions. ${ }^{21,24}$ Association of a second $\mathrm{I}^{-}$at the proximity of a $\left(\mathrm{S}^{+}, \mathrm{I}^{-}\right)$pair, as suggested by the observed kinetics, could therefore be achieved by forming a $\left(\mathrm{S}^{+}, \mathrm{I}^{-}\right) \cdots \mathrm{I}^{-}$ complex on the surface involving weak van der Waals interactions. Alternatively, adsorption of iodide at the interface might also result in the same behavior. Electrophoretic lightscattering measurements carried out with Z907Na-dyed nanoparticles scraped out of a mesoscopic sintered film showed that the derivatized surface is actually negatively charged with a typical $\zeta$-potential $\zeta=-20 \mathrm{mV}$. This result is comparable to the value of $\zeta=-30 \mathrm{mV}$ previously reported for N3-sensitized $\mathrm{TiO}_{2}$ nanoparticles. ${ }^{19}$ However, the very high ionic strength imposed by the concentrated electrolyte is expected to screen in a large extent electrostatic interactions. This would then allow negatively charged $\mathrm{I}^{-}$species to approach the surface and accumulate locally within the adsorbed dye layer.

In contrast with the results obtained with the N820 dye, the dependence of the regeneration reaction kinetics upon iodide concentration observed for the Z907Na complex sensitizer does not follow a Langmuir behavior (Figure 1). Rather, a superlinear increase (concave upward function) of the regeneration rate is observed with a very low initial slope. The value of $1 / t_{1 / 2}$ measured at $\left[\mathrm{I}^{-}\right]_{\mathrm{b}}=0.5 \mathrm{~mol} \mathrm{~L}^{-1}$ corresponds to a pseudo-first-order rate constant $k^{\prime \prime}=8.7 \times$ $10^{3} \mathrm{~s}^{-1}, 1$ order of magnitude smaller than the $k^{\prime \prime}=1.0 \times 10^{5}$ $\mathrm{s}^{-1}$ value obtained for $\mathrm{N} 820$ at the same iodide bulk concentration. This effect can clearly be assigned to the two nonyl chains grafted onto one of the ligands of $\mathrm{Z} 907 \mathrm{Na}$ that hinder the access of iodide to the active reaction sites. In the perspective of eq 14 , the repulsive interaction between the dyed surface and $\mathrm{I}^{-}$species results in a depleted surface concentration where $\left[\mathrm{I}^{-}\right]_{\mathrm{s}}<\left[\mathrm{I}^{-}\right]_{\mathrm{b}}$. The local slope of the function $1 / t_{1 / 2}=f\left(\left[\mathrm{I}^{-}\right]_{\mathrm{b}}\right)$ increases continuously with the iodide bulk concentration. For $\left[\mathrm{I}^{-}\right]_{\mathrm{b}}>1.5 \mathrm{~mol} \mathrm{~L}^{-1}$, this slope appears to reach a maximum, suggesting the surface concentration eventually equilibrates with the bulk iodide concentration $\left[\mathrm{I}^{-}\right]_{\mathrm{s}}$ $\approx\left[\mathrm{I}^{-}\right]_{\mathrm{b}}$. This allows for the extraction of a second-order rate constant for the regeneration reaction from eq 14 :

$$
k_{2}=\ln (2) \cdot\left(1 / t_{1 / 2}\right) /\left[\mathrm{I}^{-}\right]_{\mathrm{b}}=\ln (2) \cdot \text { slope }=6.4 \times 10^{4} \mathrm{~mol}^{-1} \mathrm{Ls}^{-1}
$$

If one postulates that the latter value of the second-order rate constant $k_{2}$ applies also to the N820 dye case, a saturation surface concentration of iodide $\left[\mathrm{I}^{-}\right]_{\mathrm{s} \text { max }}=3.4 \mathrm{~mol} \mathrm{~L}^{-1}$ is derived from eq 14 and the fitted value of $k^{\prime \prime}=k_{\max }$. Such a concentration corresponds to $2.05 \mathrm{I}^{-}$anions $/ \mathrm{nm}^{3}$, implying the minimum mean interparticle distance between two iodide anions adsorbed within the dyed layer is $\left(2.05 \mathrm{~nm}^{-3}\right)^{-1 / 3}=0.8$ $\mathrm{nm}$. This value corresponds approximately to the separation distance between two sensitizer molecules on the surface and thus is compatible with the picture of one iodide anion associated with each $\left(\mathrm{S}^{+}, \mathrm{I}^{-}\right)$pair.

The comparison of the regeneration dynamics measured for both ruthenium dyes N820 and Z907Na shows that increasing the length of the substituting alkyl chains results in a reduction of the rate constant. This can be related to the results reported for a series of amphiphilic ruthenium dyes with alkyl chains, whose length was varied from $\mathrm{C}_{1}$ up to $\mathrm{C}_{18}$. At a constant concentration $\left[\mathrm{I}^{-}\right]_{\mathrm{b}}=0.6 \mathrm{~mol} \mathrm{~L}{ }^{-1}$, the observed trend clearly indicates that the regeneration dynamics is related to the alkyl chain barrier length: the longer the barrier, the slower the regeneration process. ${ }^{38}$

Organic Dyes. The time evolution of the population of the oxidized form $\mathrm{S}^{+}$of the four D- $\pi$-A organic dyes C201, C203,
C204, and C205 was monitored upon pulsed photoexcitation and subsequent ultrafast charge injection into the conduction band of $\mathrm{TiO}_{2}$. Excitation wavelengths ranged from 505 to 530 $\mathrm{nm}$. Probe wavelengths were chosen on the basis of photoinduced absorption spectra (Figure S2 of Supporting Information) and ranged between 650 and $700 \mathrm{~nm}$.

Figure 2 displays the inverse of the half-reaction times measured for the regeneration of the dyes ground states as a

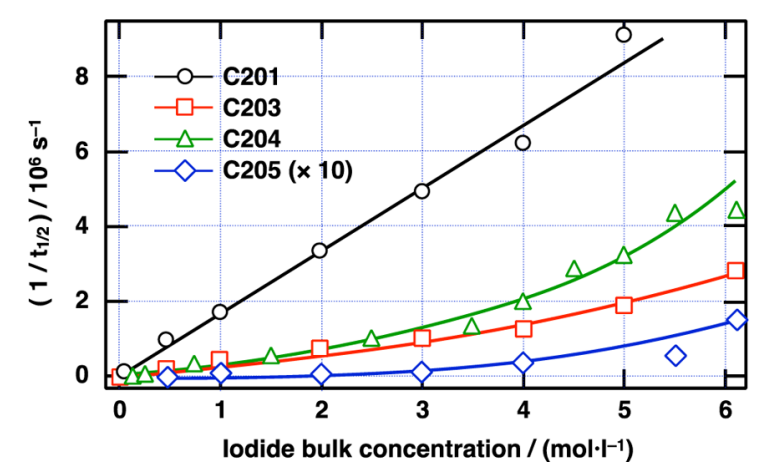

Figure 2. Inverse of the half-reaction time $1 / t_{1 / 2}$ for the regeneration of oxidized dyes C201, C203, C204, and C205 measured as a function of the bulk iodide concentration. The ordinate of data points recorded for the C205 dye is expanded by a factor of 10 for ease of reading.

function of the iodide concentration in the bulk of the electrolyte $\left[\mathrm{I}^{-}\right]_{\mathrm{b}}$. Iodide concentrations spanning from 0.1 to $6.1 \mathrm{~mol} \mathrm{~L}^{-1}$ were obtained experimentally by diluting the ionic liquid PMII in MPN solvent.

In the absence of iodide, the half-reaction times for the decay of $\mathrm{S}^{+}$through their recombination with conduction band electrons in $\mathrm{TiO}_{2}$ were between $t_{1 / 2}=245 \mu$ s for C203 and 1 $\mathrm{ms}$ for C201. The dynamics of the back electron-transfer process in those cases is therefore quite comparable to that measured for $\mathrm{Ru}^{\mathrm{II}}$ complex dyes. Upon addition of iodide in the electrolyte, the kinetics of the $\mathrm{S}^{+}$population due to the regeneration reaction was observed to be quite different for the various dyes, with $1 / t_{1 / 2}$ values spreading over two orders of magnitude. C201 yielded the higher rate constant, while C205 appeared to be regenerated very slowly. C203 and C204 exhibit similar intermediate time scales for the regeneration of their ground states by iodide. Data reported in Figure 2 show that none of the four organic dyes display a sublinear iodide concentration-dependence of the rate constants that would point to an attractive behavior. Half-reaction times measured for the C201 dye sensitizer exhibit a clean linear dependence upon the iodide bulk concentration, suggesting $\left[\mathrm{I}^{-}\right]_{\mathrm{s}}=\left[\mathrm{I}^{-}\right]_{\mathrm{b}}$ at all concentrations. The slope of the line fitted through the experimental points yields a second-order rate constant $k_{2}=$ $\ln (2)$.slope $=1.14 \times 10^{6} \mathrm{~mol}^{-1} \mathrm{~L} \mathrm{~s}^{-1}$. This latter value is approximately 18 times larger than that of $k_{2}$ derived for the $\mathrm{Ru}^{\mathrm{II}}$ complex dyes. It even exceeds by a factor of 2 the initial slope measured for N820 dye at $\left[\mathrm{I}^{-}\right]_{\mathrm{b}} \rightarrow 0$. An intrinsically faster reaction rate could be rationalized by a shorter reaction distance, a more favorable thermodynamics, and/or a reduced reorganization energy associated with the electron-transfer process in the organic dyes. ${ }^{39}$

Because the driving force of the one electron-transfer process is rather small, the latter should display a normal Marcus kinetic behavior. ${ }^{40}$ Heteroleptic $\mathrm{Ru}^{\mathrm{II}}$-complex dyes, whose structure is comparable to that of $\mathrm{N} 3$, such as $\mathrm{N} 820$ and $\mathrm{Z} 907 \mathrm{Na}$, are characterized by a standard oxidation potential in solution $\phi^{0}=$ 
$+1.10 \mathrm{~V} / \mathrm{SHE}^{41}$ The oxidation potential of all four $\mathrm{D}-\pi$-A organic dyes must as well be very similar, as this characterizes the common triarylamine donor function. A value $\phi^{0}=+1.00$ $\mathrm{V} / \mathrm{SHE}$ has been reported for C204. ${ }^{42}$ This $100 \mathrm{mV}$ difference, with an increased driving force in favor of the ruthenium compounds, is incompatible with the observed dynamics. The difference in thermodynamic driving forces for the reduction of $\mathrm{S}^{+}$does not appear to provide a rationale for the observed change of the intrinsic rate of the reaction. As well, the reorganization energy for electron transfer is expected to be significantly smaller in $\mathrm{Ru}^{\mathrm{II}}$ complex dyes than for $\mathrm{D}-\pi$-A organic molecules. ${ }^{39} \mathrm{An}$ increase of the reaction rate in the case of the C201 sensitizer must then be related to other factors, including molecular geometry affecting the approach of iodide anions to the reaction center and the equilibrium constant $K_{1}$ for the formation of $\left(\mathrm{S}^{+}, \mathrm{I}^{-}\right)$pairs.

Half-reaction times for $\mathrm{C} 204$ evolve in a way similar to those for Z907Na. The slope of the function $1 / t_{1 / 2}=f\left(\left[\mathrm{I}^{-}\right]\right)$increases continuously from a value $<3 \times 10^{5} \mathrm{~mol}^{-1} \mathrm{~L} \mathrm{~s}^{-1}$ at $\left[\mathrm{I}^{-}\right]_{\mathrm{b}}<1$ mol L ${ }^{-1}$ to eventually approach a linear dependence at high iodide concentrations. The second-order rate constant derived from the local slope measured at $\left[\mathrm{I}^{-}\right]_{\mathrm{b}}=6 \mathrm{~mol} \mathrm{~L}^{-1}$ is $k_{2} \approx 10^{6}$ $\mathrm{mol}^{-1} \mathrm{~L} \mathrm{~s}^{-1}$, comparable to the result obtained with C201 dye. This behavior is again indicative of a repulsive interaction between $\mathrm{I}^{-}$anions and the derivatized oxide surface. It is even more evident for $\mathrm{C} 203$ and $\mathrm{C} 205$ sensitizers, as $\left[\mathrm{I}^{-}\right]_{\mathrm{b}}$ dependence of the regeneration half-reaction times in the two latter cases appears to follow a quadratic function over the whole concentration range in accordance with the rate law of eq 9. This suggests the equilibrium constant $K_{1}$ for the formation of $\left(\mathrm{S}^{+}, \mathrm{I}^{-}\right)$pairs for the four D- $\pi$-A organic dyes decreases markedly in the order C201 C C204 > C203 》 C205.

The disparity of the regeneration reaction rates observed between the organic dyes should be related to their molecular structure. The fluorene groups grafted onto the triarylamine hole-acceptor moiety are similar for the four dyes. Therefore, the ease of access of iodide anions to the central amine, where we expect the positive charge to be localized in the $S^{+}$species, should be comparable in all cases. The electron-accepting cyanoacrylate unit, also allowing for anchoring the sensitizer molecule onto the $\mathrm{TiO}_{2}$ surface, is identical for the four dyes. No difference in the mode and geometry of adsorption onto the surface should therefore be relevant. However, the different $\pi$-conjugated bridges equipping the $\mathrm{C} 20 \mathrm{x}$ dyes can be distinguished in terms of the potential binding sites they might offer to iodide anions. By analogy with $\mathrm{Ru}^{\mathrm{II}}$-complex dyes, where the thiocyanate ligands appeared to play an important role in the dye-electrolyte interaction, sulfur atoms contained in the thiophene rings are likely to control the equilibrium of the association of iodide with the oxidized sensitizer and the formation of $\left(\mathrm{S}^{+}, \mathrm{I}^{-}\right)$pairs. Therefore, we propose a qualitative explanation based on the interaction between the sulfur atoms of the $\pi$-conjugated bridges and iodide. This interaction renders relevant the electrostatic potentials of these bridging groups. Despite the dielectric medium, local electrostatic interactions at short distance could alter the availability of sulfur sites for binding iodide and hence modify the equilibrium constant of eq 6 .

Figure $3 \mathrm{~A}$ provides a schematic representation of the structure of the ground state of the four dyes (S), whose geometries were optimized by using MO-G (MOPAC) semiempirical molecular orbital calculation method along

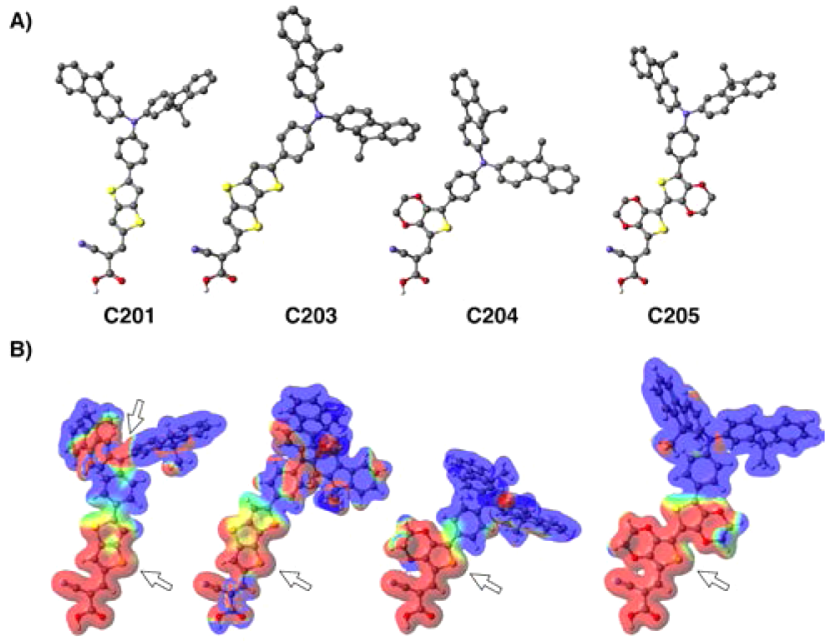

Figure 3. (A) Ball-and-stick molecular models of the four D- $\pi$-A organic dyes used in this study. Gray, blue, red, and yellow balls represent $\mathrm{C}, \mathrm{N}, \mathrm{O}$, and $\mathrm{S}$ atoms, respectively. Hydrogen atoms were omitted for simplification. Molecular geometries were optimized by applying MO-G semiempirical calculation method along with the PM6 parameters set. (B) Electrostatic potential mapped onto electron density surface as computed for the oxidized form of the molecules by using MOS-F (PM6) method. Zones of positive potential (attractive for an iodide anion) are colored in red, while zones of negative potential (repulsive for $\mathrm{I}^{-}$) are colored in blue. Rainbow colors correspond to intermediate potential values.

with PM6 Hamiltonian (Fujitsu Scigress v.3.1.6 software). Figure $3 \mathrm{~B}$ shows the electrostatic potential mapped on the electronic density surfaces for the different dye molecules in their oxidized state $\left(\mathrm{S}^{+}\right)$as computed using MOS-F (PM6) semiempirical method. For C201, the electrostatic potential map suggests that the sulfur atom next to the cyanoacrylate anchor (marked by an arrow in Figure 3B) is more likely to bind one iodide anion. The same is true for C203. In this case, the much lower regeneration rate could be explained by the curved geometry of the molecule on the surface. Neighboring C203 sensitizers anchored on $\mathrm{TiO}_{2}$ may form a tight barrier deterring the approach of $\mathrm{I}^{-}$next to the sulfur binding sites. This steric hindrance effect is also likely to take place for C204 (Figure 3A). It could, however, be partially compensated by a shorter distance separating the sulfur binding site and the nitrogen atom in the triarylamine moiety, which is likely to speed up the electron-transfer process. While for C201 this distance is $9.4 \AA$ and extends to $10.8 \AA$ for C203, it is only $6.8 \AA$ in C204. The C205 molecule gathers several detrimental characteristics justifying its very slow regeneration kinetics. The electrostatic potential map indicates that the oxidized amine moiety in C205 is globally negatively charged. The approach of iodide anions to the reaction site must then be restricted. Steric hindrance due to the slanted conformation of the molecule on the oxide surface and a large distance of $10.9 \AA$ separating the sulfur potential binding site from the oxidized amine also contribute to the same result.

\section{CONCLUSION}

The study of the kinetics of reduction by iodide of oxidized dye sensitizer molecules adsorbed on $\mathrm{TiO}_{2}$ contributes to the understandings of the light-absorber regeneration mechanism in liquid electrolyte DSSCs. In this work, we monitored the time evolution of the population of dye-oxidized states $\mathrm{S}^{+}$by 
time-resolved spectroscopy. The observed decay kinetics reflects the reduction of $\mathrm{S}^{+}$species by $\mathrm{I}^{-}$anions and takes place in the microsecond time domain. The time resolution of our experimental setup $(<10 \mathrm{~ns})$, as well as femtosecond pump-probe spectroscopy experiments carried out on similar systems, ${ }^{43}$ allowed the conclusion that there is no faster kinetic step for dye regeneration. In the presence of a large excess of iodide, the reduction dynamics was found to consistently follow a pseudo-first-order rate law. Details regarding the mechanism of the regeneration reaction were deduced from the dependence of $\mathrm{S}^{+}$reduction rate constant upon bulk iodide concentration $\left[\mathrm{I}^{-}\right]_{\mathrm{b}}$ in the electrolyte.

Two different behaviors were observed among the various $\mathrm{Ru}^{\mathrm{II}}$ complex and organic dye sensitizers examined. The first one corresponds to a sublinear function of the pseudo-firstorder rate constant measured for increasing values of $\left[\mathrm{I}^{-}\right]_{\mathrm{b}}$. It is interpreted as being due to an associative mechanism involving $\left(\mathrm{S}^{+}, \mathrm{I}^{-}\right) \cdots \mathrm{I}^{-}$pairs prior to electron transfer. This behavior translates into a steeper slope of the pseudo-first-order rate constant function at low $\left[\mathrm{I}^{-}\right]_{\mathrm{b}}$ values, indicating local iodide concentrations larger than those in the bulk. It was observed in particular for $\mathrm{Ru}^{\mathrm{II}}$ complex dyes deprived from long alkyl chain substituents such as N820. The formation of $\left(\mathrm{S}^{+}, \mathrm{I}^{-}\right) \cdots \mathrm{I}^{-}$ complexes apparently follows a Langmuir isotherm with an equilibrium constant $K_{\mathrm{ad}}=3.4 \mathrm{M}^{-1}$ and a saturation concentration of adsorbed iodide $\left[\mathrm{I}^{-}\right]_{\mathrm{s}, \max }=3.4 \mathrm{M}$.

A second behavior was observed with $\mathrm{Ru} \mathrm{u}^{\mathrm{II}}$ complex dyes and organic D- $\pi$-A push-pull sensitizers exposing repulsive molecular moieties to the electrolyte and forming tight barriers deterring the approach of iodide anions. A superlinear dependence of pseudo-first-order rate constants upon bulk iodide concentration is observed generally in this case, suggesting the iodide concentration within the dye layer is generally lower than that in the bulk of the electrolyte. At high bulk concentration, these concentrations tend to equilibrate, yielding a linear function and a second-order rate constant for the reduction process varying from $k_{2}=6.4 \times 10^{4} \mathrm{~mol}^{-1} \mathrm{~L} \mathrm{~s}^{-1}$ for $\mathrm{Z} 907 \mathrm{Na} \mathrm{Ru}{ }^{\mathrm{II}}$ complex and $k_{2}=1.1 \times 10^{6} \mathrm{~mol}^{-1} \mathrm{~L} \mathrm{~s}^{-1}$ for C201 organic D- $\pi$-A dye. A qualitative rationale of the kinetic behaviors based on the molecular structures of the dyes is proposed.

For the purpose of designing new dyes to be used with iodide-based electrolytes in dye-sensitized solar cells, it is inferred that the insertion of an easily accessible site capable of binding $\mathrm{I}^{-}$anions at a short distance to the moiety carrying the lowest unoccupied molecular orbital of the dye might be a good strategy.

\section{ASSOCIATED CONTENT}

\section{S Supporting Information}

Sample of transient absorbance measurement and photoinduced absorption spectra. This material is available free of charge via the Internet at http://pubs.acs.org.

\section{AUTHOR INFORMATION}

\section{Corresponding Author}

*E-mail: joel.teuscher@epfl.ch.

\section{Notes}

The authors declare no competing financial interest.

\section{ACKNOWLEDGMENTS}

The authors thank P. Comte for the preparation of the $\mathrm{TiO}_{2}$ paste and R. Humphry-Baker for fruitful discussion. Financial support by the Swiss National Science Foundation is gratefully acknowledged. M.X. and P.W. thank the National 973 Program (2011CBA00702) and the National Science Foundation of China (51203150, 51125015, and 91233206) for financial support.

\section{REFERENCES}

(1) Grätzel, M. Photoelectrochemical Cells. Nature 2001, 414, 338344.

(2) O'Regan, B. C.; Grätzel, M. A Low-Cost, High-Efficiency SolarCell Based on Dye-Sensitized Colloidal $\mathrm{TiO}_{2}$ Films. Nature 1991, 353, 737-740.

(3) Wenger, B.; Grätzel, M.; Moser, J.-E. Rationale for Kinetic Heterogeneity of Ultrafast Light-Induced Electron Transfer from $\mathrm{Ru}$ (II) Complex Sensitizers to Nanocrystalline $\mathrm{TiO}_{2}$. J. Am. Chem. Soc. 2005, 127, 12150-12151.

(4) Huber, R.; Moser, J.-E.; Grätzel, M.; Wachtveitl, J. Real-Time Observation of Photoinduced Adiabatic Electron Transfer in Strongly Coupled Dye/Semiconductor Colloidal Systems with a 6 fs Time Constant. J. Phys. Chem. B 2002, 106, 6494-6499.

(5) Ardo, S.; Meyer, G. J. Photodriven Heterogeneous Charge Transfer with Transition-Metal Compounds Anchored to $\mathrm{TiO}_{2}$ Semiconductor Surfaces. Chem. Soc. Rev. 2009, 38, 115-164.

(6) Chen, C.-Y.; Wang, M.; Li, J. Y.; Pootrakulchote, N.; Alibabaei, L.; Ngoc-Le, C. H.; Decoppet, J.-D.; Tsai, J. H.; Grätzel, C.; Wu, C. G. Highly Efficient Light-Harvesting Ruthenium Sensitizer for Thin-Film Dye-Sensitized Solar Cells. ACS Nano 2009, 3, 3103-3109.

(7) Bessho, T.; Zakeeruddin, S. M.; Yeh, C.-Y.; Diau, E. W.-G.; Grätzel, M. Highly Efficient Mesoscopic Dye-Sensitized Solar Cells Based on Donor-Acceptor-Substituted Porphyrins. Chem.-Eur. J. 2010, 49, 6646-6649.

(8) Boschloo, G.; Hagfeldt, A. Characteristics of the Iodide/Triiodide Redox Mediator in Dye-Sensitized Solar Cells. Acc. Chem. Res. 2009, $42,1819-1826$

(9) Yella, A.; Lee, H. W.; Tsao, H. N.; Yi, C.; Chandiran, A. K.; Nazeeruddin, M. K.; Diau, E. W.-G.; Yeh, C.-Y.; Zakeeruddin, S. M.; Grätzel, M. Porphyrin-Sensitized Solar Cells with Cobalt (II/III)Based Redox Electrolyte Exceed 12\% Efficiency. Science 2011, 334, 629-634.

(10) Yum, J.-H.; Baranoff, E.; Kessler, F.; Moehl, T.; Ahmad, S.; Bessho, T.; Marchioro, A.; Ghadiri, E.; Moser, J.-E.; Yi, C.; et al. A Cobalt Complex Redox Shuttle for Dye-Sensitized Solar Cells with High Open-Circuit Potentials. Nat. Commun. 2012, 3, 631.

(11) Farnum, B. H.; Jou, J. J.; Meyer, G. J. Visible Light Generation of I-I Bonds by Ru-Tris (Diimine) Excited States. Proc. Natl. Acad. Sci. U.S.A. 2012, 109, 15628-15633.

(12) Jeon, J.; Goddard, W. A., III; Kim, H. Inner-Sphere ElectronTransfer Single Iodide Mechanism for Dye Regeneration in DyeSensitized Solar Cells. J. Am. Chem. Soc. 2013, 135, 2431-2434.

(13) Dye-Sensitized Solar Cells; Kalyanasundaram, K., Ed.; EPFL Press: Lausanne, Switzerland, 2010.

(14) Clifford, J. N.; Palomares, E.; Nazeeruddin, M. K.; Grätzel, M.; Durrant, J. R. Dye Dependent Regeneration Dynamics in Dye Sensitized Nanocrystalline Solar Cells: Evidence for the Formation of a Ruthenium Bipyridyl Cation/Iodide Intermediate. J. Phys. Chem. C 2007, 111, 6561-6567.

(15) Mengesha Tefashe, U.; Nonomura, K.; Vlachopoulos, N.; Hagfeldt, A.; Wittstock, G. Effect of Cation on Dye Regeneration Kinetics of N719-Sensitized $\mathrm{TiO}_{2}$ Films in Acetonitrile-Based and Ionic-Liquid-Based Electrolytes Investigated by Scanning Electrochemical Microscopy. J. Phys. Chem. C 2012, 116, 4316-4323.

(16) Anderson, A. Y.; Barnes, P. R. F.; Durrant, J. R.; O’Regan, B. C. Quantifying Regeneration in Dye-Sensitized Solar Cells. J. Phys. Chem. C 2011, 115, 2439-2447. 
(17) Martiniani, S.; Anderson, A. Y.; Law, C.; O’Regan, B. C.; Barolo, C. New Insight into the Regeneration Kinetics of Organic Dye Sensitised Solar Cells. Chem. Commun. 2012, 48, 2406-2408.

(18) O’Regan, B. C.; Durrant, J. R. Kinetic and Energetic Paradigms for Dye-Sensitized Solar Cells: Moving from the Ideal to the Real. Acc. Chem. Res. 2009, 42, 1799-1808.

(19) Pelet, S.; Moser, J.-E.; Grätzel, M. Cooperative Effect of Adsorbed Cations and Iodide on the Interception of Back Electron Transfer in the Dye Sensitization of Nanocrystalline $\mathrm{TiO}_{2}$. J. Phys. Chem. B 2000, 104, 1791-1795.

(20) Clark, C.; Marton, A.; Meyer, G. J. Evidence for Static Quenching of MLCT Excited States by Iodide. Inorg. Chem. 2005, 44, 3383-3385.

(21) Agrell, H.; Lindgren, J.; Hagfeldt, A. Coordinative Interactions in a Dye-Sensitized Solar Cell. J. Photochem. Photobiol., A 2004, 164, $23-27$.

(22) Fitzmaurice, D.; Frei, H. Transient Near-Infrared Spectroscopy of Visible-Light Sensitized Oxidation of $\mathrm{I}^{-}$at Colloidal $\mathrm{TiO}_{2}$. Langmuir 1991, 7, 1129-1137.

(23) O'Regan, B. C.; Lopez-Duarte, I.; Martinez-Diaz, M. V.; Forneli, A.; Albero, J.; Morandeira, A.; Palomares, E.; Torres, T.; Durrant, J. R. Catalysis of Recombination and Its Limitation on Open Circuit Voltage for Dye Sensitized Photovoltaic Cells Using Phthalocyanine Dyes. J. Am. Chem. Soc. 2008, 130, 2906-2907.

(24) Greijer, H.; Lindgren, J.; Hagfeldt, A. Resonance Raman Scattering of a Dye-Sensitized Solar Cell: Mechanism of Thiocyanato Ligand Exchange. J. Phys. Chem. B 2001, 105, 6314-6320.

(25) Privalov, T.; Boschloo, G.; Hagfeldt, A.; Svensson, P. H.; Kloo, L. A Study of the Interactions Between $\mathrm{I}^{-} / \mathrm{I}_{3}{ }^{-}$Redox Mediators and Organometallic Sensitizing Dyes in Solar Cells. J. Phys. Chem. C 2009, $113,783-790$.

(26) Schiffmann, F.; VandeVondele, J.; Hutter, J.; Urakawa, A.; Wirz, R.; Baiker, A. An Atomistic Picture of the Regeneration Process in Dye Sensitized Solar Cells. Proc. Natl. Acad. Sci. U.S.A. 2010, 107, 48304833.

(27) Tuikka, M.; Hirva, P.; Rissanen, K.; Korppi-Tommola, J.; Haukka, M. Halogen Bonding-A Key Step in Charge Recombination of the Dye-Sensitized Solar Cell. Chem. Commun. 2011, 47, 44994501 .

(28) Qin, H.; Wenger, S.; Xu, M.; Gao, F.; Jing, X.; Wang, P.; Zakeeruddin, S. M.; Grätzel, M. An Organic Sensitizer with a Fused Dithienothiophene Unit for Efficient and Stable Dye-Sensitized Solar Cells. J. Am. Chem. Soc. 2008, 130, 9202-9203.

(29) Vlachopoulos, N.; Liska, P.; Augustynski, J.; Grätzel, M. Very Efficient Visible-Light Energy Harvesting and Conversion by Spectral Sensitization of High Surface-Area Polycrystalline Titanium-Dioxide Films. J. Am. Chem. Soc. 1988, 110, 1216-1220.

(30) Zhang, Z.; Ito, S.; Moser, J.-E.; Zakeeruddin, S. M.; Grätzel, M. Influence of Iodide Concentration on the Efficiency and Stability of Dye-Sensitized Solar Cell Containing Non-Volatile Electrolyte. ChemPhysChem 2009, 10, 1834-1838.

(31) Montanari, I.; Nelson, J.; Durrant, J. R. Iodide Electron Transfer Kinetics in Dye-Sensitized Nanocrystalline $\mathrm{TiO}_{2}$ Films. J. Phys. Chem. B 2002, 106, 12203-12210.

(32) Zakeeruddin, S. M.; Grätzel, M. Solvent-Free Ionic Liquid Electrolytes for Mesoscopic Dye-Sensitized Solar Cells. Adv. Funct. Mater. 2009, 19, 2187-2202.

(33) Wang, M.; Xu, M.; Shi, D.; Li, R.; Gao, F.; Zhang, G.; Yi, Z.; Humphry-Baker, R.; Wang, P.; Zakeeruddin, S. M.; et al. HighPerformance Liquid and Solid Dye-Sensitized Solar Cells Based on a Novel Metal-Free Organic Sensitizer. Adv. Mater. 2008, 20, 44604463.

(34) Saragi, T. P. I.; Spehr, T.; Siebert, A.; Fuhrmann-Lieker, T.; Salbeck, J. Spiro Compounds for Organic Optoelectronics. Chem. Rev. 2007, 107, 1011-1065.

(35) Moser, J.-E.; Noukakis, D.; Bach, U.; Tachibana, Y.; Klug, D.; Durrant, J.; Humphry-Baker, R.; Grätzel, M. Comment on "Measurement of Ultrafast Photoinduced Electron Transfer from Chemically
Anchored $\mathrm{Ru}-$ Dye Molecules into Empty Electronic States in a Colloidal Anatase $\mathrm{TiO}_{2}$ Film”. J. Phys. Chem. B 1998, 102, 3649-3650.

(36) Snaith, H. J.; Karthikeyan, C. S.; Petrozza, A.; Teuscher, J.; Moser, J.-E.; Nazeeruddin, M. K.; Thelakkat, M.; Grätzel, M. High Extinction Coefficient "Antenna" Dye in Solid-State Dye-Sensitized Solar Cells: A Photophysical and Electronic Study. J. Phys. Chem. C 2008, 112, 7562-7566.

(37) Wang, P.; Zakeeruddin, S. M.; Moser, J.-E.; Nazeeruddin, M. K.; Sekiguchi, T.; Grätzel, M. A Stable Quasi-Solid-State Dye-Sensitized Solar Cell with an Amphiphilic Ruthenium Sensitizer and Polymer Gel Electrolyte. Nat. Mater. 2003, 2, 402-407.

(38) Kroeze, J. E.; Hirata, N.; Koops, S. E.; Nazeeruddin, M. K.; Schmidt-Mende, L.; Grätzel, M.; Durrant, J. R. Alkyl Chain Barriers for Kinetic Optimization in Dye-Sensitized Solar Cells. J. Am. Chem. Soc. 2006, 128, 16376-16383.

(39) Moser, J.-E. Dynamics of Interfacial and Surface Electron Transfer Processes. In Dye-Sensitized Solar Cells; Kalyanasundaram, K., Ed.; EPFL Press: Lausanne, Switzerland, 2011; pp 403-456.

(40) Feldt, S. M.; Wang, G.; Boschloo, G.; Hagfeldt, A. Effects of Driving Forces for Recombination and Regeneration on the Photovoltaic Performance of Dye-Sensitized Solar Cells Using Cobalt Polypyridine Redox Couples. J. Phys. Chem. C 2011, 115, 2150021507.

(41) Nazeeruddin, M. K.; Kay, A.; Rodicio, I.; Humphry-Baker, R.; Muller, E.; Liska, P.; Vlachopoulos, N.; Grätzel, M. Conversion of Light to Electricity by cis- $\mathrm{X}_{2} \mathrm{Bis}\left(2,2^{\prime}\right.$-bipyridyl-4,4-'dicarboxylate)ruthenium(II) Charge-Transfer Sensitizers $\left(\mathrm{X}=\mathrm{Cl}^{-}, \mathrm{Br}^{-}, \mathrm{I}^{-}, \mathrm{Cn}^{-}\right.$, and $\mathrm{SCN}^{-}$) on Nanocrystalline $\mathrm{TiO}_{2}$ Electrodes. J. Am. Chem. Soc. 1993, 115, 6382-6390.

(42) Xu, M.; Wenger, S.; Bala, H.; Shi, D.; Li, R.; Zhou, Y.; Zakeeruddin, S. M.; Grätzel, M.; Wang, P. Tuning the Energy Level of Organic Sensitizers for High-Performance Dye-Sensitized Solar Cells. J. Phys. Chem. C 2009, 113, 2966-2973.

(43) Teuscher, J.; Decoppet, J.-D.; Punzi, A.; Zakeeruddin, S. M.; Moser, J.-E.; Grätzel, M. Photoinduced Interfacial Electron Injection Dynamics in Dye-Sensitized Solar Cells under Photovoltaic Operating Conditions. J. Phys. Chem. Lett. 2012, 3, 3786-3790. 


\section{Supplementary Information: Kinetics of the Regeneration by lodide of Dye-Sensitizers Adsorbed on Mesoporous Titania}

Joël Teuscher,${ }^{a, b^{*}}$ Arianna Marchioro,${ }^{a, b}$ Julien Andrès,,${ }^{a}$ Lö̈c Roch, ${ }^{a}$ Mingfei Xu, ${ }^{c}$ Shaik M. Zakeeruddin, ${ }^{b}$ Peng Wang, ${ }^{c}$ Michael Grätzel, ${ }^{b}$ and Jacques-E. Moser ${ }^{a}$

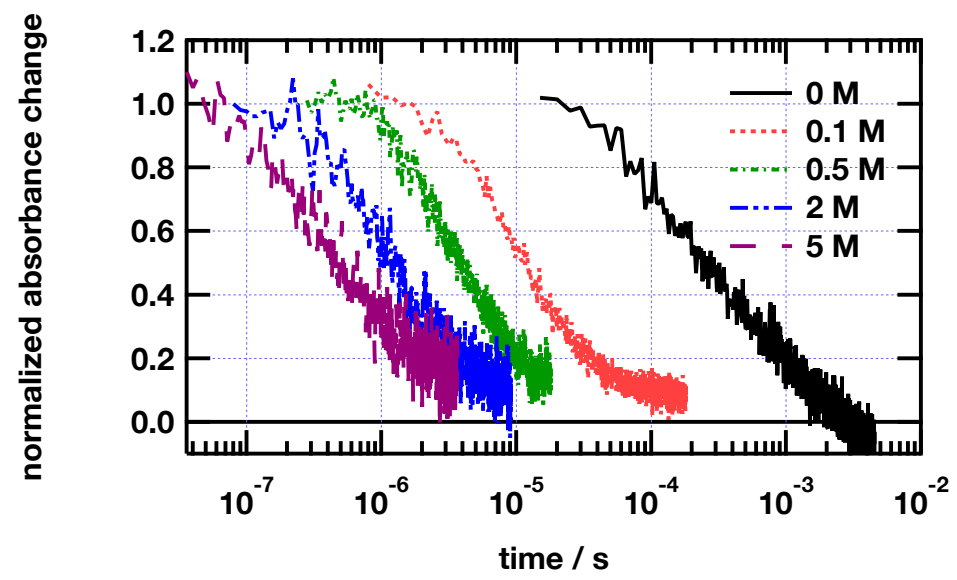

Figure S1: Normalized transient absorbance traces of dye C203|TiO ${ }_{2}, \lambda_{\mathrm{ex}}=525 \mathrm{~nm}$, $\lambda_{\text {obs }}=650 \mathrm{~nm}$.

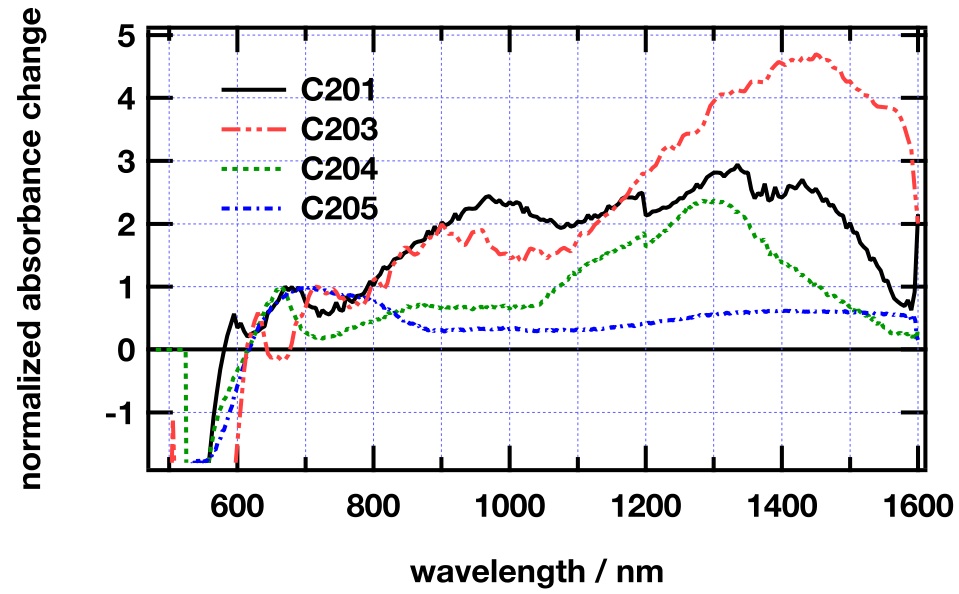

Figure S2: PIA spectra of $\mathrm{C} 201\left|\mathrm{TiO}_{2}(-), \mathrm{C}_{203}\right| \mathrm{TiO}_{2}(-\cdots), \mathrm{C}_{204}\left|\mathrm{TiO}_{2}(\cdots), \mathrm{C} 205\right| \mathrm{TiO}_{2}$ $(-\cdot), \lambda_{\mathrm{ex}}=470 \mathrm{~nm}$ at $9 \mathrm{~Hz}$ in air. 